\title{
Suspension Culture and Somatic Embryogenesis of Korean Pine
}

\author{
Chunxue Peng ${ }^{1,2}$, Fang Gao ${ }^{1,2}$, Hao Wang ${ }^{1,2}$, Iraida Nikolaevna Tretyakova ${ }^{3}$, \\ Alexander Mikhaylovich Nosov $^{4,5}$, Hailong Shen ${ }^{1,2, *}$ and Ling Yang ${ }^{1,2, *}$ \\ ${ }^{1}$ State Key Laboratory of Tree Genetics and Breeding, School of Forestry, Northeast Forestry University, Harbin, 150040, China \\ ${ }^{2}$ State Forestry and Grassland Administration Engineering Technology Research Center of Korean Pine, Harbin, 150040, China \\ ${ }^{3}$ Laboratory of Forest Genetics and Breeding, Institution of the Russian Academy of Sciences, V. N. Sukachev Institute of Forest \\ Siberian Branch of RAS, Krasnoyarsk, 660036, Russia \\ ${ }^{4}$ Department of Cell Biology and Institute of Plant Physiology, K. A. Timiryazev Russian Academy of Sciences, Moscow, 127276, \\ Russia \\ ${ }^{5}$ Department of Plant Physiology, Biological Faculty, Lomonosov Moscow State University, Moscow, 119991, Russia \\ *Corresponding Authors: Hailong Shen. Email: shenhl-cf@nefu.edu.cn; Ling Yang. Email: yangl-cf@nefu.edu.cn
}

Received: 25 December 2020 Accepted: 09 April 2021

\begin{abstract}
Korean pine is an important afforestation tree species in Northeast China, which has a high ecological and economic value. Although regeneration of somatic embryogenesis using immature zygotic embryos of Korean pine as explants has been successful, it cannot be applied to automation and large-scale production. Therefore, we urgently need a method that can increase the output of somatic embryos (SEs) to meet the needs of large-scale production. We used Korean pine 1-1 and 1-100 cell lines as research materials to evaluate the effects of inoculum-density, culture time, orbiting speed, vessel volume, plant growth regulator (PGR) concentration, and carbon source on the proliferation of embryogenic tissue (ET). The somatic embryogenesis ability of ET cultured in different liquid suspension media was also evaluated. We found that during liquid suspension culture of Korean pine ET, the sedimented cell volume (SCV), fresh weight (FW) and dry weight (DW) were affected by inoculumdensity, culture time, orbiting speed, 2,4-D concentration, 6-BA concentration and carbon source type. Fourty $\mathrm{mg} \cdot \mathrm{mL}^{-1}$ ET were transferred to a $200 \mathrm{~mL}$ Erlenmeyer flask containing $20 \mathrm{~mL}$ liquid medium, and cultured at $100 \mathrm{rpm} / \mathrm{min}$ for 14 days to obtain the maximum proliferation. In addition, we also found that SCV, FW and DW were higher when PGRs were reduced in the liquid suspension medium. The substitution of maltose for sucrose resulted in slow growth of cultures and limited SE yield (13 SEs $\left.\mathrm{g}^{-1} \mathrm{FW}\right)$. Although culture proliferation was high at $50 \mathrm{rpm}$, SE yield was inhibited by $48 \%$ compared with $100 \mathrm{rpm}\left(50 \mathrm{rpm}=33 \mathrm{SEs} \mathrm{g}^{-1} \mathrm{FW} ; 100\right.$ $\left.\mathrm{rpm} / \mathrm{min}=70 \mathrm{SEs} \mathrm{g}^{-1} \mathrm{FW}\right)$. Cultivation in low-concentration $\mathrm{PGR}\left(1.15 \mu \mathrm{M} \cdot \mathrm{L}^{-1} 2,4-\mathrm{D}, 0.25 \mu \mathrm{M} \cdot \mathrm{L}^{-1} 6-\mathrm{BA}\right)$

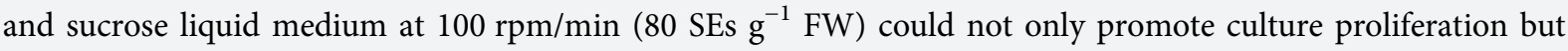
also increase SE yield. The determination of the suspension culture scheme of Korean pine ET provides a reference for further expansion to bioreactor culture in the future and lays a foundation for the automation and scale of somatic embryogenesis of Korean pine.
\end{abstract}

\section{KEYWORDS}

Pinus koraiensis Sieb.et Zucc; embryogenic tissue; liquid suspension medium; cell proliferation 


$\begin{array}{ll}\text { Abbreviations } \\ \text { ET: } & \text { embryogenic tissue } \\ \text { SE(s): } & \text { Somatic Embryo(s) } \\ \text { SCV: } & \text { Sedimented Cell Volume } \\ \text { FW: } & \text { Fresh Weight } \\ \text { DW: } & \text { Dry Weight } \\ \text { PGR: } & \text { Plant Growth Regulator } \\ \text { MG: } & \text { Megagametophyte }\end{array}$

\section{Introduction}

Korean pine (Pinus koraiensis Sieb.et Zucc.) is the dominant species of broad-leaved Korean pine forests and it has an extremely important ecological value. It is the main afforestation tree species in Northeast China, with excellent wood and seeds, and extremely high economic value [1]. However, with the increasing demand for wood, the natural populations of Korean pine have declined sharply, and Korean pine was listed as a low-risk species by the International Union for Conservation of Nature (IUCN) 2013 Red List [2]. The development of breeding technology for large-scale clone production is imminent to restore and expand the resources of P. koraiensis, and give full play to the ecological function and economic value of this species. Somatic embryogenesis, as the most potential propagation technique in conifers, has been applied in many species such as Pinus densiflora [3], Scots pine [4], and Brazilian pine [5]. At present, the somatic embryogenesis technology of Korean pine has made staged progress, and the tissue induction system with mature and immature zygotic embryos of Korean pine as explants has been successfully established [6,7]. Among them, the embryogenic tissue obtained from the immature zygotic embryos of Korean pine has the ability of somatic embryogenesis [8]. But there are still some practical problems that restrict the occurrence of high frequency of Korean pine somatic embryos (SEs). For example, Korean pine SE yield is low and synchronization is difficult [9]. Therefore, we urgently need a method that can increase the yield of SEs to meet large-scale production.

Early research found that the main reason for limiting the synchronization of SEs during somatic embryogenesis is that the early SEs in the ET are at different stages of development [10]. Filonova et al. [11] and Elhiti et al. [12] divided the proliferation process into three stages (PEMI, PEMII, and PEMIII) based on morphology and cytology. Among them, only early SEs in PEMIII stage can respond to maturation, thus limiting the yield of maturation SEs. In conifers, the metabolic activity of the internal tissues of ET decreases as the proliferation time increases, and only a few early SEs on the surface can respond to maturation, resulting in a decrease in ET utilization [13]. The liquid culture medium can effectively reduce the aggregation of cells by shaking, and make the distribution of nutrients and metabolites uniform. The cells can quickly absorb nutrients increase cell proliferation rate [14]. In addition, liquid suspension culture is conducive to breaking down ET into smaller ET aggregates, effectively increasing ET proliferation and SE yield. Liquid culture can not only provide a scale-up option in bioreactors but also reduces labor force participation, which is necessary for large-scale automated production [15,16], as well as permit to achieve synchronization of cultures and further improve the conversion rate of transgenic technology [17]. At present, suspension culture technology has been reported in many species, such as Norway spruce [10] and Anthurium andraeanum [16]. It has been reported that the inoculum-density in liquid culture is an important factor affecting cell growth and development. Low inoculum-density could lead to low proliferation, while high inoculum-density could inhibit cell growth [18]. Similarly, the volume and orbiting speed of the Erlenmeyer flask can regulate the growth of cells by affecting the amount of gas exchange and hydrodynamic stress [14]. In the semi-solid 
medium, the diffusion of nutrients is a slow process, and a concentration gradient will be formed around the cells, which will slow down growth, so liquid medium is suitable for medium components with lower concentration [18]. Therefore, the determination of these factors affecting cell growth and development is necessary for the successful establishment of Korean pine suspension culture systems.

The purpose of our study was to establish a suspension culture system of Korean pine, comprehensively evaluate the effects of inoculum-density, culture time, orbiting speed, vessel volume, PGR concentration, and carbon source type on culture proliferation. On this basis, the responsiveness of the proliferating ET in the liquid medium to the maturation medium was further studied. It provides the parameter basis for further application of automated dispersion systems and new temporary immersion bioreactor for Korean pine, and lays a foundation for realizing large-scale commercial reproduction of Korean pine.

\section{Materials and Methods}

\subsection{Plant Material}

Immature zygotic embryos of Korean pine are used as explants induced by ET. For the induction method, see Gao et al. [7]. To promote ET proliferation, ET was transferred to proliferation medium, which consisted of DCR [19] supplemented with $0.5 \mathrm{mg} \mathrm{L}^{-1}$ 2,4-dichlorophenoxyacetic acid (2,4-D), $0.1 \cdot \mathrm{mg} \mathrm{L}^{-1}$ 6-benzylaminopurine (6-BA), $30 \cdot \mathrm{g} \mathrm{L}^{-1}$ sucrose, $0.5 \cdot \mathrm{g} \mathrm{L}^{-1} \mathrm{~L}$-glutamine, $0.5 \cdot \mathrm{g} \mathrm{L}^{-1}$ casein enzymatic chydrolysate and $4 \mathrm{~g} \cdot \mathrm{L}^{-1}$ gellan gum. The $\mathrm{pH}$ of the medium was then adjusted to 5.8 before sterilization. ET was subcultured every 2 weeks, with the culture in darkness at $24 \pm 1^{\circ} \mathrm{C}$. After 3 months of multiplication culture, we selected $1-100$ and 1-1 cell lines with the potential for somatic embryogenesis for follow-up experiments.

\subsection{Establishment of Suspension Cultures}

\subsubsection{Effect of Inoculum-Density and Culture Time on Cell Proliferation}

1-100 and 1-1 cell lines were used to test the effect of inoculum-density $(10,20,30,40$ and $\left.50 \mathrm{mg} \cdot \mathrm{mL}^{-1}\right)$ and culture time $(0,7,14$ and 21 days) on the proliferation of ET. After the ET was cultured in semi-solid medium for 7 days, 200, 400, 600, 800, and $1000 \mathrm{mg}$ of fresh ET were collected and transferred to a $100 \mathrm{~mL}$ Erlenmeyer flask with $20 \mathrm{ml}$ of liquid DCR medium. The Erlenmeyer flask was then placed in a shaking incubator $(100 \mathrm{rpm} / \mathrm{min})$ (HZQ-F100, Harbin, China) under darkness at $24 \pm 1{ }^{\circ} \mathrm{C}$. On the 0 th, 7 th, 14 th, and 21 st days of culture, three flasks were randomly taken and the culture in the flask was poured into a $50 \mathrm{~mL}$ graduated tube and allowed to stand for 30 min to measure the settled cell volume (SCV). Then, the suspension was placed in a Büchner funnel and the excess liquid was filtered to obtain the fresh weight $(\mathrm{FW})$. Finally, the culture was dried in a $60^{\circ} \mathrm{C}$ oven for $24 \mathrm{~h}$ to determine the dry weight (DW). Each treatment was performed in triplicate.

\subsubsection{Effect of Orbiting Speed on Cell Proliferation}

$1-100$ and $1-1$ cell lines were used to test the effect of orbiting speed $(50,100$ and $150 \mathrm{rpm})$ on cell proliferation. The growth rate of 1-100 and 1-1cell lines in suspension culture was evaluated. After 2 weeks of culture, SCV, FW and DW parameters were measured. Each treatment was performed in triplicate.

\subsubsection{Effect of Vessel Volume on Cell Proliferation}

1-100 and 1-1 cell lines were used to test the effect of vessel volume (100 and $200 \mathrm{~mL}$ Erlenmeyer flasks) on cell proliferation. The growth rate of 1-100 and 1-1 cell lines in suspension culture was evaluated. After 2 weeks of culture, SCV, FW and DW parameters were measured. Each treatment was performed in triplicate. 


\subsubsection{Effect of PGR Concentration and Carbon Source on Cell Proliferation}

$1-100$ and $1-1$ cell lines were used to test the effect of PGR concentration on cell proliferation, including normal- (PGR concentration in a semi-solid medium, $2.3 \mu \mathrm{M} \cdot \mathrm{L}^{-1} 2,4-\mathrm{D}, 0.5 \mu \mathrm{M} \cdot \mathrm{L}^{-1}$ 6-BA), and higher- $\left(4.6 \mu \mathrm{M} \cdot \mathrm{L}^{-1} 2,4-\mathrm{D}, 1 \mu \mathrm{M} \cdot \mathrm{L}^{-1}\right.$ 6-BA) and lower-concentrations of PGR $\left(1.15 \mu \mathrm{M} \cdot \mathrm{L}^{-1} 2,4-\mathrm{D}\right.$, $\left.0.25 \mu \mathrm{M} \cdot \mathrm{L}^{-1} 6-\mathrm{BA}\right)$. In addition, the effects of sucrose and maltose $(25 \mathrm{~g})$ were also tested on growth parameters at standard concentrations $(25 \mathrm{~g})$ in DCR medium. The SCV, FW and DW parameters were measured after 2 weeks of cultivation. Each treatment was performed in triplicate.

\subsection{Somatic Embryo Maturation}

According to the method described by Peng et al. [9], the somatic embryogenesis and maturation ability of the suspension culture was tested. The excess liquid medium in the suspension culture was filtered out, and $50 \mathrm{mg}$ ET samples were taken out and suspended in the proliferation liquid medium without PGR (DCR basic medium supplemented with $25 \mathrm{mg} \cdot \mathrm{L}^{-1}$ sucrose). The suspension was poured on qualitative filter paper that has been sterilized under high temperature and high pressure, and it was then dried. After removing the excess liquid, the filter paper was transferred to the maturation medium $(\mathrm{mLV}$ basic medium) [20], supplemented with $80 \mu \mathrm{M} \cdot \mathrm{L}^{-1} \mathrm{ABA}, 0.2 \mathrm{M} \cdot \mathrm{L}^{-1}$ sucrose, $0.5 \cdot \mathrm{g} \mathrm{L}^{-1} \mathrm{~L}$-glutamine, $0.5 \cdot \mathrm{g} \mathrm{L}^{-1}$ casein enzymatic chydrolysate and $1.2 \%$ gellan gum (Phytagel ${ }^{\mathrm{TM}}$, Sigma-Aldrich)), and cultured in the darkness at $25^{\circ} \mathrm{C}$ for $10-12$ weeks. Each treatment was repeated 10 times, and the SE maturation capacity was recorded as the number of SEs with normal morphology obtained per $\mathrm{g}$ of ET FW. Subsequently, the obtained cotyledonary SEs were collected and placed in a 6-well multiplace (Corning-Costar, USA), placed in a refrigerator at $4^{\circ} \mathrm{C}$ for 1 week, and then transferred to germination medium ( $\mathrm{mLV}$ as the basic medium, supplemented with $1 \mathrm{~g} \cdot \mathrm{L}^{-1}$ activated carbon, $0.2 \mathrm{M} \cdot \mathrm{L}^{-1}$ sucrose and $0.4 \%$ gellan gum). The regenerated plantlets were obtained after darkness culture at $25^{\circ} \mathrm{C}$ for 4 weeks.

\subsection{Morphological Observation}

We used a microscope (SZX-ILLB2-200, Japan) to observe the ET obtained from immature zygotic embryos, and collected ET on the 7th day of proliferation culture. It was stained using $2 \%(\mathrm{~m} / \mathrm{v})$ acetyl group Carmine, compressed on a glass slide, covered with a coverslip, and observed under a Zeiss A× microscope (Carl Zeiss, Jena, Germany). At the same time, we used a camera (Nikon700, Japan) to record the changes in the ET suspension culture process. In addition, we also observed the maturation cotyledonary SEs and regenerated plantlets of Korean pine under a stereomicroscope (SZX-ILLB2-200, Japan).

\subsection{Statistical Analysis}

The effects of factors were evaluated by one-way analysis of variance (ANOVA) and Duncan's multiple comparisons using SPSS software (2010, V. 19.0: SPSS, Inc., Cary, NC, USA). Sigmaplot (v12.5, SYSTAT, San Jose, California, USA) and Microsoft Visio 2007 software were used for drawing.

\section{Results}

\subsection{Establishment of Suspension Culture}

\subsubsection{Inoculum-density and Culture Time}

Two cell lines $(1-100,1-1)$ were used to test their cell proliferation rate under different inoculumdensities. It was found that there were significant differences in SCV and DW between both cell lines (SCV: $P=0.038$; DW: $P=0.014)$ but there was no significant difference in FW $(P=0.084)$. Between them, the 1-100 cell line had high SCV, FW and DW than the 1-1 cell line. In addition, there were very significant differences in the three growth parameters (SCV, FW, and DW) among different inoculumdensities They have the lowest SCV and DW values at $20 \mathrm{mg} \cdot \mathrm{mL}^{-1}(\mathrm{SCV}=12 \mathrm{~mL}, \mathrm{FW}=1.57 \mathrm{~g}, \mathrm{DW}=$ $0.103 \mathrm{~g})$, and reach the highest values at $40 \mathrm{mg} \cdot \mathrm{mL}^{-1}(\mathrm{SCV}=15 \mathrm{~mL}, \mathrm{FW}=1.96 \mathrm{~g}, \mathrm{DW}=0.132 \mathrm{~g})$. 
There was no significant interaction between the cell line and inoculum-density on the three growth parameters (SCV, FW and DW) (SCV: $P=0.449$; FW: $P=0.295$; DW: $P=0.100$ ) (Tab. 1).

Table 1: The effect of cell lines and inoculum-density on the proliferation of ET

\begin{tabular}{llll}
\hline \multirow{2}{*}{ Factor } & \multicolumn{3}{c}{ Growth parameter } \\
\cline { 2 - 4 } & Settled cell volume $(\mathrm{mL})$ & Fresh weight $(\mathrm{g})$ & Dry weight $(\mathrm{g})$ \\
\hline Cell lines & $13.8 \pm 0.5$ & $1.83 \pm 0.08$ & $0.127 \pm 0.005$ \\
$1-100$ & $12.5 \pm 0.3$ & $1.65 \pm 0.06$ & $0.118 \pm 0.003$ \\
$1-1$ & & & \\
Inoculum-density & $12.0 \pm 0.4 \mathrm{c}$ & $1.57 \pm 0.07 \mathrm{~b}$ & $0.103 \pm 0.004 \mathrm{~b}$ \\
20 & $12.3 \pm 0.5 \mathrm{bc}$ & $1.57 \pm 0.08 \mathrm{~b}$ & $0.112 \pm 0.003 \mathrm{~b}$ \\
30 & $15.0 \pm 0.6 \mathrm{a}$ & $1.96 \pm 0.07 \mathrm{a}$ & $0.132 \pm 0.007 \mathrm{a}$ \\
40 & $13.4 \pm 0.4 \mathrm{~b}$ & $1.87 \pm 0.09 \mathrm{a}$ & $0.130 \pm 0.006 \mathrm{a}$ \\
50 & & & \\
$P$-value & 0.038 & 0.084 & 0.014 \\
Cell lines & 0.001 & 0.003 & 0.002 \\
Inoculum-density & 0.449 & 0.295 & 0.1 \\
Cell lines $\times$ Inoculum-density & & & \\
\hline
\end{tabular}

Notes: $100 \mathrm{~mL}$ Erlenmeyer flask, $20 \mathrm{~mL}$ liquid medium, and $100 \mathrm{rpm} / \mathrm{min}$ for 14 days; the growth rate is expressed as the settled cell volume (SCV, $\mathrm{mL}$ ), fresh weight (FW, g) and dry weight (DW, g).

Two cell lines $(1-100,1-1)$ were used to test their growth curve changes under different inoculumdensities. We found that at an inoculation density of $40 \mathrm{mg} \cdot \mathrm{mL}^{-1}, \mathrm{SCV}(1-100=16.2 \mathrm{~mL} ; 1-1=$ $13.7 \mathrm{~mL})$, FW $(1-100=2.09 \mathrm{~g} ; 1-1=1.83 \mathrm{~g})$ and DW $(1-100=0.143 \mathrm{~g} ; 1-1=0.120 \mathrm{~g})$ reached their maximum values after 14 days of culture. SCV increased sharply from 0-14 days, and gradually decreased from 14-21 days. FW increased sharply from 0-7 d, while 7-21 increased or decreased slowly. DW increased sharply from 0 to 7 days, increased slowly from 7 to 14 days, and remained unchanged after 14 days. At the same time, we conducted a correlation analysis of SCV, FW and DW at $40 \mathrm{mg} \cdot \mathrm{mL}^{-1}$. As a result, there was a significant correlation between $\mathrm{SCV}, \mathrm{FW}$ and $\mathrm{DW}\left(\mathrm{SCV}^{*} \mathrm{FW}, P=\right.$ $\left.0.002 ; \mathrm{SCV}^{*} \mathrm{DW}, P=0.001 ; \mathrm{DW}^{*} \mathrm{FW}, P=0.020\right)$. In summary, we found that the optimal inoculation density of suspension culture of Korean pine ET was $40 \mathrm{mg} \cdot \mathrm{mL}^{-1}$, and the optimal culture time was 14 days (Fig. 1).

\subsubsection{Vessel Volume}

Two cell lines $(1-100,1-1)$ were used to test their cell proliferation rate under two vessel volumes. DW was significantly different $(P=0.045)$ between both vessel volumes, but there was no significant difference in SCV and FW. Among them, the SCV, FW and DW were higher in the $200 \mathrm{~mL}$ than the $100 \mathrm{~mL}$ Erlenmeyer flask $(\mathrm{SCV}=14.2, \mathrm{FW}=1.7, \mathrm{DW}=0.098)$. In addition, there was no significant interaction between cell lines and vessel volumes (SCV: $P=0.437$; FW: $P=0.149$; DW: $P=0.077$ ) (Tab. 2). 


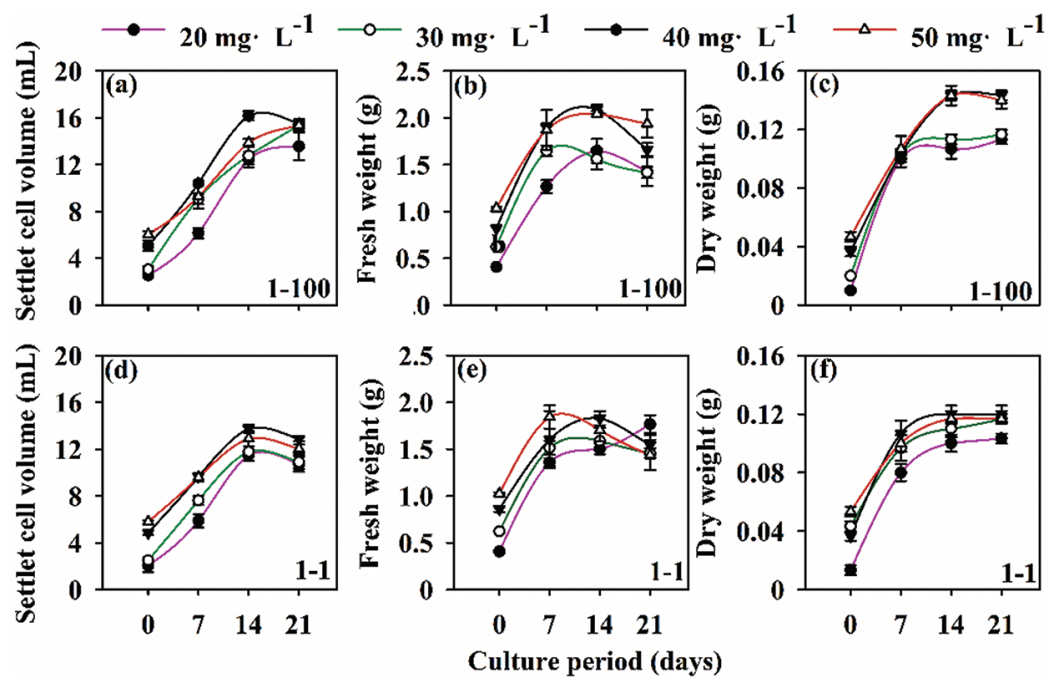

Figure 1: Growth curves of Korean pine cell lines 1-100 and 1-1 at different cell densities. Note: settled cell volume (SCV); fresh weight (FW); dry weight (DW). The inoculum-density was $20,30,40,50 \mathrm{mg} \cdot \mathrm{mL}^{-1}$. The suspension was incubated at an orbiting speed of $100 \mathrm{rpm}$ for 21 days

Table 2: The effect of vessel volume on the proliferation of Korean pine ET

\begin{tabular}{|c|c|c|c|}
\hline \multirow[t]{2}{*}{ Factor } & \multicolumn{3}{|c|}{ Growth parameter } \\
\hline & Settled cell volume $(\mathrm{mL})$ & Fresh weight $(\mathrm{g})$ & Dry weight $(\mathrm{g})$ \\
\hline \multicolumn{4}{|l|}{ Cell lines } \\
\hline $1-100$ & $13.7 \pm 0.54$ & $1.69 \pm 0.08$ & $0.082 \pm 0.009$ \\
\hline $1-1$ & $13.6 \pm 0.36$ & $1.62 \pm 0.05$ & $0.092 \pm 0.010$ \\
\hline \multicolumn{4}{|l|}{ Vessel volume } \\
\hline EF100 & $13.1 \pm 0.26$ & $1.61 \pm 0.07$ & $0.075 \pm 0.005$ \\
\hline EF200 & $14.2 \pm 0.48$ & $1.7 \pm 0.06$ & $0.098 \pm 0.010$ \\
\hline \multicolumn{4}{|l|}{$P$-value } \\
\hline Cell lines & 0.927 & 0.453 & 0.34 \\
\hline Vessel volume & 0.095 & 0.355 & 0.045 \\
\hline Cell lines $\times$ Vessel volume & 0.437 & 0.149 & 0.077 \\
\hline
\end{tabular}

\subsubsection{Orbiting Speed}

Two cell lines $(1-100,1-1)$ were used to test the effect of orbiting speed on cell proliferation. There were significant differences in SCV and FW between both cell lines (SCV: $P=0.019$; FW: $P \leq 0.001$ ), but there was no significant difference in DW $(P=0.253)$. Among them, the $1-100$ cell line has higher SCV and FW than the 1-1 cell line. With the increase of orbiting speed, the three growth parameters were significantly reduced. SCV, FW and DW reached the highest at $50 \mathrm{rpm}(\mathrm{SCV}=16.1 \mathrm{~mL}, \mathrm{FW}=2.24, \mathrm{DW}=0.153)$ (Fig. 2A), while at $150 \mathrm{rpm}$ (Fig. 2C) SCV, FW and DW were the lowest (SCV $=11.8 \mathrm{~mL}, \mathrm{FW}=1.80$, $\mathrm{DW}=0.112$ ). In addition, there was no significant interaction between the cell line and orbiting speed on the three growth parameters (Tab. 3). 

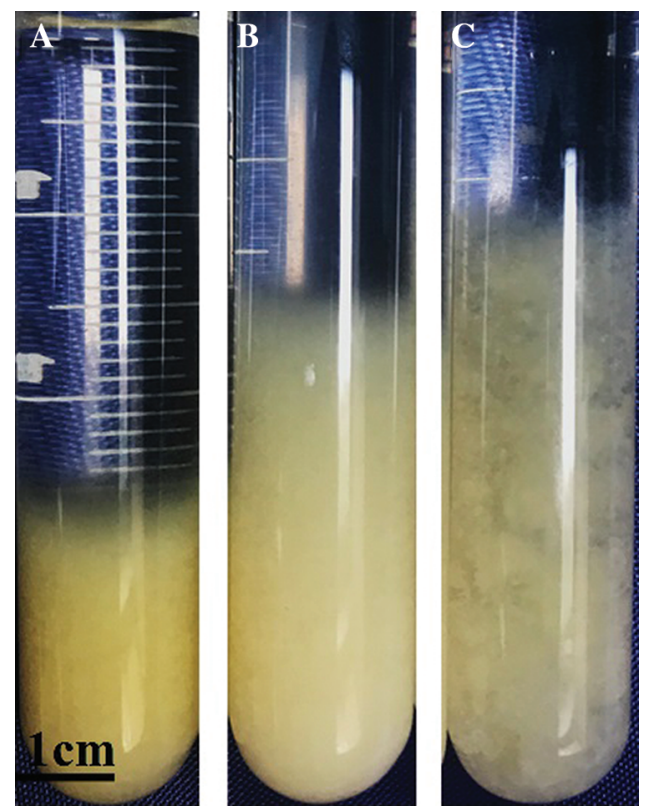

Figure 2: Effect of orbiting speed on the proliferation of Korean pine ET. Note: A: 50 rpm; B: 100 rpm; C: $150 \mathrm{rpm} . \mathrm{Bar}=1 \mathrm{~cm}$

Table 3: Effect of orbiting speed on the proliferation of Korean pine ET

\begin{tabular}{|c|c|c|c|}
\hline \multirow[t]{2}{*}{ Factor } & \multicolumn{3}{|c|}{ Growth parameter } \\
\hline & Settled cell volume $(\mathrm{mL})$ & Fresh weight $(\mathrm{g})$ & Dry weight $(\mathrm{g})$ \\
\hline \multicolumn{4}{|l|}{ Cell lines } \\
\hline $1-100$ & $14.8 \pm 0.8$ & $1.72 \pm 0.1$ & $0.136 \pm 0.008$ \\
\hline $1-1$ & $13.7 \pm 0.6$ & $1.50 \pm 0.04$ & $0.129 \pm 0.006$ \\
\hline \multicolumn{4}{|l|}{ Orbiting speed } \\
\hline 50 & $16.1 \pm 0.5 \mathrm{a}$ & $2.24 \pm 0.09 \mathrm{a}$ & $0.153 \pm 0.003 \mathrm{a}$ \\
\hline 100 & $15.0 \pm 0.6 b$ & $1.96 \pm 0.07 b$ & $0.132 \pm 0.007 \mathrm{~b}$ \\
\hline 150 & $11.8 \pm 0.2 \mathrm{c}$ & $1.80 \pm 0.08 \mathrm{c}$ & $0.112 \pm 0.006 \mathrm{c}$ \\
\hline \multicolumn{4}{|l|}{$P$-value } \\
\hline Cell lines & 0.019 & 0.000 & 0.253 \\
\hline Orbiting speed & 0.001 & 0.001 & 0.001 \\
\hline Cell lines $\times$ Orbiting speed & 0.104 & 0.891 & 0.088 \\
\hline
\end{tabular}

In addition, we observed a significant difference in cellular sediment at different speeds. At $50 \mathrm{rpm}$, loose bulk sediments were obtained to form higher SCV; at $100 \mathrm{rpm}$, dense pushing sediments were obtained to form smaller SCV; at $150 \mathrm{rpm}$, denser packed sediments were obtained to form the smallest SCV. 
SCV and FW of the 1-100 and 1-1 cell lines had the same response to different orbiting speeds. SCV and FW of the 1-1 cell lines were lower than those in the 1-100 cell line (Fig. 3). In addition, DW of 1-1 was not greatly affected by the rotation speed, but at $100 \mathrm{rpm}$ where DW was lower in the 1-1 than in the 1-100 cell line (Fig. 3). When the orbiting speed was increased from $100 \mathrm{rpm} / \mathrm{min}$ to $150 \mathrm{rpm} / \mathrm{min}$, DW of $1-100$ cell line decreased by $40 \%$, and DW of $1-1$ cell line decreased by $9 \%$. Interestingly, $50 \mathrm{rpm}$ yields the highest values for the three parameters, with no significant differences between lines. (Fig. 3).
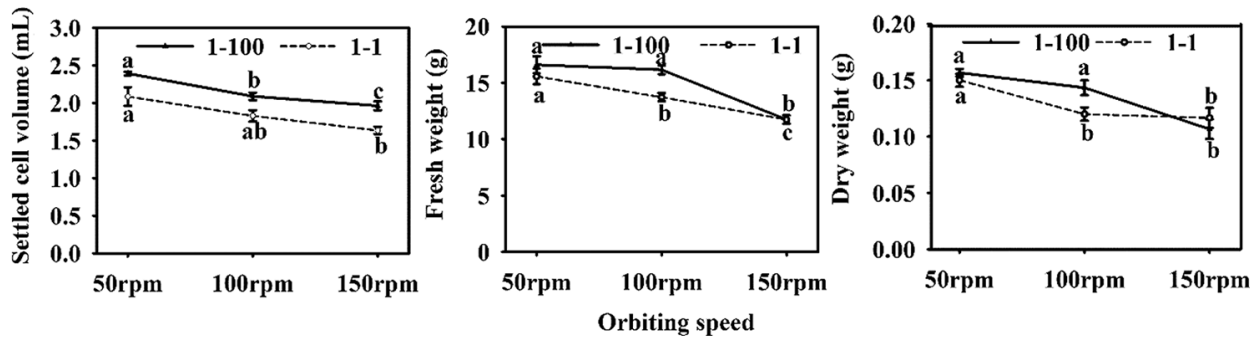

Figure 3: ETs proliferation of Korean pine cell lines 1-100 and 1-1 at different orbital speeds. Note: Different letters on the 1-100 and 1-1 cell lines within each orbital speed indicate significant differences between cell lines

\subsubsection{PGR Concentration}

Under various PGR concentrations, SCV and FW of different cell lines were significantly different (SCV, $P=0.007$; FW, $P=0.007$ ), and the SCV, FW and DW of the 1-100 cell line were higher than those in the 11 cell line. FW and DW also showed significant differences among PGR concentrations (FW, $P=0.009$; DW, $P=0.001$ ). Similar SCV and FW values were obtained at low and normal PGR concentrations, while lower $\mathrm{SCV}$ and FW values were obtained at high concentrations. In addition, there was a significant interaction between cell lines and PGR concentrations on FW $(P=0.08)$ (Tab. 4).

Table 4: Effect of PGR concentration on the proliferation of Korean pine ET

\begin{tabular}{|c|c|c|c|}
\hline \multirow[t]{2}{*}{ Factor } & \multicolumn{3}{|c|}{ Growth parameter } \\
\hline & Settled cell volume $(\mathrm{mL})$ & Fresh weight $(\mathrm{g})$ & Dry weight $(\mathrm{g})$ \\
\hline \multicolumn{4}{|l|}{ Cell lines } \\
\hline $1-100$ & $14.2 \pm 0.6$ & $1.72 \pm 0.1$ & $0.103 \pm 0.006$ \\
\hline $1-1$ & $12.2 \pm 0.5$ & $1.50 \pm 0.04$ & $0.098 \pm 0.007$ \\
\hline \multicolumn{4}{|l|}{ PGR concentration } \\
\hline Normal PGR & $13.1 \pm 1.1 \mathrm{ab}$ & $1.70 \pm 0.14 \mathrm{a}$ & $0.081 \pm 0.006 b$ \\
\hline Low PGR & $14.2 \pm 0.5 \mathrm{a}$ & $1.70 \pm 0.06 \mathrm{a}$ & $0.113 \pm 0.005 \mathrm{a}$ \\
\hline High PGR & $12.2 \pm 0.4 b$ & $1.43 \pm 0.04 b$ & $0.108 \pm 0.004 \mathrm{a}$ \\
\hline \multicolumn{4}{|l|}{$P$-value } \\
\hline Cell lines & 0.007 & 0.007 & 0.439 \\
\hline PGR concentration & 0.056 & 0.009 & 0.001 \\
\hline Cell lines $\times$ PGR concentration & 0.104 & 0.008 & 0.183 \\
\hline
\end{tabular}




\subsubsection{Carbon Source}

The carbon source had a significant effect on the three growth parameters of ET proliferation. When maltose was used as the carbon source, culture proliferation was lower. FW was significantly different between cell lines, but SCV and DW had no significant difference. In addition, there was no significant interaction between cell lines and carbon sources (Tab. 5).

Table 5: Effects of carbon sources on the proliferation of Korean pine ET

\begin{tabular}{|c|c|c|c|}
\hline \multirow[t]{2}{*}{ Factor } & \multicolumn{3}{|c|}{ Growth parameter } \\
\hline & Settled cell volume $(\mathrm{mL})$ & Fresh weight (g) & Dry weight $(\mathrm{g})$ \\
\hline \multicolumn{4}{|l|}{ Cell lines } \\
\hline $1-100$ & $13.7 \pm 0.5$ & $1.74 \pm 0.03$ & $0.073 \pm 0.009$ \\
\hline $1-1$ & $12.5 \pm 0.7$ & $1.51 \pm 0.07$ & $0.088 \pm 0.012$ \\
\hline \multicolumn{4}{|l|}{ Carbon source } \\
\hline Maltose & $12.0 \pm 0.48$ & $1.54 \pm 0.07$ & $0.063 \pm 0.006$ \\
\hline Sucrose & $14.2 \pm 0.47$ & $1.70 \pm 0.06$ & $0.098 \pm 0.010$ \\
\hline \multicolumn{4}{|l|}{$P$-value } \\
\hline Cell lines & 0.077 & 0.005 & 0.207 \\
\hline Carbon source & 0.005 & 0.033 & 0.013 \\
\hline Cell lines $\times$ Carbon source & 0.296 & 0.711 & 0.711 \\
\hline
\end{tabular}

\subsubsection{Subculture Type}

Subculture type (liquid and semi-solid medium) has a significant effect on the proliferation of $\mathrm{FW}$ and DW of ET (FW, $P=0.001$; DW, $P=0.002$ ). Compared with the semi-solid medium, the liquid medium showed a lower FW (1.96 g) and a higher DW $(0.132 \mathrm{~g})$. In addition, there was a significant interaction between cell lines and subculture types on FW $(P=0.003)$ (Tab. 6).

Table 6: Effects of proliferation rate in liquid $v s$. semi-solid medium

\begin{tabular}{llc}
\hline Factor & \multicolumn{2}{c}{ Growth parameter } \\
\cline { 2 - 3 } & Fresh weight $(\mathrm{g})$ & Dry weight $(\mathrm{g})$ \\
\hline Cell lines & $2.72 \pm 0.05$ & $0.133 \pm 0.003$ \\
$1-100$ & $2.11 \pm 0.06$ & $0.103 \pm 0.002$ \\
$1-1$ & & \\
Subculture procedures & $1.96 \pm 0.04$ & $0.132 \pm 0.003$ \\
Liquid medium & $2.87 \pm 0.05$ & $0.105 \pm 0.004$ \\
Semi-solid medium & & \\
$P$-value & 0.001 & 0.001 \\
Cell lines & 0.001 & 0.002 \\
Subculture procedures & 0.003 & 0.282 \\
Cell lines $\times$ Subculture procedures & & \\
\hline
\end{tabular}

Note: $200 \mathrm{~mL}$ Erlenmeyer flask, $20 \mathrm{~mL}$ liquid medium, after $100 \mathrm{rpm}$ culture for $14 \mathrm{~d}$. The growth rate is expressed as fresh weight (FW, g) and dry weight (DW, g). 


\subsection{Somatic Embryo Maturation}

ET after suspension culture was used for maturation of SEs; suspension culture conditions affected the yield of SE (Tab. 7). Compared with the control group ( $68 \mathrm{SEs} \cdot \mathrm{g}^{-1} \mathrm{FW}$ obtained on semi-solid medium), the number of SEs obtained at $100 \mathrm{rpm}$ was the highest $\left(70 \mathrm{SEs} \cdot \mathrm{g}^{-1} \mathrm{FW}\right)$, and the number of SEs obtained at $50 \mathrm{rpm} / \mathrm{min}$ was the lowest (33 SEs $\cdot \mathrm{g}^{-1} \mathrm{FW}$ ). There was no significant change in the number of SEs when cultured with different PGR concentration $(P=0.933)$ compared with the control. In addition, the difference of carbon sources during ET proliferation significantly affected the number of SE maturation; maltose as a carbon source during suspension culture significantly inhibited SE maturation $\left(13 \cdot \mathrm{SEs}^{-1} \mathrm{FW}\right)$.

Table 7: Effects of orbiting speed, PGR concentration and carbohydrate used for ET proliferation on somatic embryo maturation of Korean pine

\begin{tabular}{|c|c|c|c|c|c|}
\hline $\begin{array}{l}\text { Orbiting speed } \\
\mathrm{rpm} / \mathrm{min}\end{array}$ & $\begin{array}{l}\text { somatic embryo } \\
\left(\text { SEs g }^{-1} \text { f.m.) }\right.\end{array}$ & $\begin{array}{c}\text { PGR } \\
\text { concentration }\end{array}$ & $\begin{array}{l}\text { somatic embryo } \\
\left(\mathrm{SEs} \mathrm{g}^{-1} \text { f.m.) }\right.\end{array}$ & Carbohydrate & $\begin{array}{l}\text { somatic embryo } \\
\left(\text { SEs g }^{-1} \text { f.m.) }\right.\end{array}$ \\
\hline $\mathrm{CK}$ & $68 \pm 21$ & $\mathrm{CK}$ & $68 \pm 21$ & CK & $68 \pm 21 \mathrm{a}$ \\
\hline 50 & $33 \pm 13$ & PGR & $60 \pm 15$ & Sucrose & $80 \pm 15 a$ \\
\hline 100 & $70 \pm 15$ & H-PGR & $60 \pm 18$ & Maltose & $13 \pm 7 b$ \\
\hline 150 & $66 \pm 8$ & L-PGR & $73 \pm 18$ & & \\
\hline$P$-value & 0.247 & & 0.933 & & 0.01 \\
\hline
\end{tabular}

Note: CK: Normal proliferation culture conditions, $200 \mathrm{~mL}$ Erlenmeyer flask, $20 \mathrm{~mL}$ liquid medium, and somatic embryo maturation after 14 days of cultivation. Different letters in the table indicate significant differences between the different carbon sources.

\subsection{Observation of Somatic Embryogenesis of Korean Pine}

The seeds (the female gametophyte contains immature zygotic embryos) of Korean pine were used as explants and cultured in the induction medium for about 1 month to obtain ET (Fig. 4a). Thereafter, the ET was cultured on proliferation medium (Fig. 4b). After collecting ET on the 7th day of proliferation culture for microscopic observation, we found that there were early SEs in the ET (Fig. 4c). ET was cultured in suspension after 2 times of proliferation culture (Figs. 4d-4f). After 14 days of suspension culture, ET was transferred to maturation medium for SE maturation (Fig. 4h). After 2 months of cultivation, we obtained cotyledonary SEs. The cotyledonary SEs were placed in $4^{\circ}$ refrigerators for 1 week and then germinated at room temperature for 2 months to obtain regenerated plantlets (Fig. 4f).

\section{Discussion}

Suspension culture system is usually established by suspending ET in liquid medium. Early reports pointed out that the inoculum-density was critical to the successful establishment of suspension culture [21]. The inoculum-density in Picea sitchensis was $4 \mathrm{mg} \cdot \mathrm{mL}^{-1}$ and in Douglas fir was $120 \mathrm{mg} \cdot \mathrm{mL}^{-1}$ [22]. In our study, when the inoculum-density of Korean pine was $40 \mathrm{mg} \cdot \mathrm{mL}^{-1}$, it had better proliferation than at $20-30 \mathrm{mg} \cdot \mathrm{mL}^{-1}$. In addition, when the inoculum-density exceeded $40 \mathrm{mg} \cdot \mathrm{ml}^{-1}$, the proliferation began to decrease. Similar results also existed in Stone pine, and the proliferation was higher at $20 \mathrm{mg} \cdot \mathrm{mL}^{-1}$ than at $30 \mathrm{mg} \cdot \mathrm{mL}^{-1}$ [22]. In Pinus nigra, it was found that when the inoculum weight was less than $0.5 \mathrm{~g}$, ET could not develop normally, and it could proliferate significantly only at 1 or $2.5 \mathrm{~g}$ inoculum [21]. This indicates that the inoculum-density will vary depending on thespecies and the experimental design. At the same time, it was also found in Japanese pine that in high inoculum-density culture, ET could proliferate in the form of small spherical cell aggregates and could not further develop into early SEs. However, low inoculum-density culture could promote ET development into early SEs. It shows that the inoculum-density can regulate the formation of ET with uniform morphology and developmental stages [23]. In addition, the determination of the growth curve of the culture is very 
important for the optimal time of subculture and the evaluation of the performance at different growth stages [24]. In our study, the growth of Korean pine ET could be described as a S-shaped curve. After 14 days of culture at the optimal inoculum-density $\left(40 \mathrm{mg} \cdot \mathrm{ml}^{-1}\right), \mathrm{SCV}, \mathrm{FW}$ and $\mathrm{DW}$ all reached the maximum values. There was a similar phenomenon in the study of spruce and stone pine, where SCV reached the maximum after 20 days of culture in spruce [25], and DW reached the maximum after 28 days of culture in stone pine [22]. At the same time, it was observed that the ET growth curve had a long logarithmic phase during the suspension culture of Korean pine. This may be because the culture material was ET instead of individual cells. In the liquid medium, the outer layer of ET was in complete contact with the medium. However, due to the physical limitation of the outer layer of ET, the inner cells may be restricted while rotating. During the liquid culture, the ET often fell apart into smaller parts that adapted to the liquid culture condition thereby slowly reaching the flexion of proliferation [16].

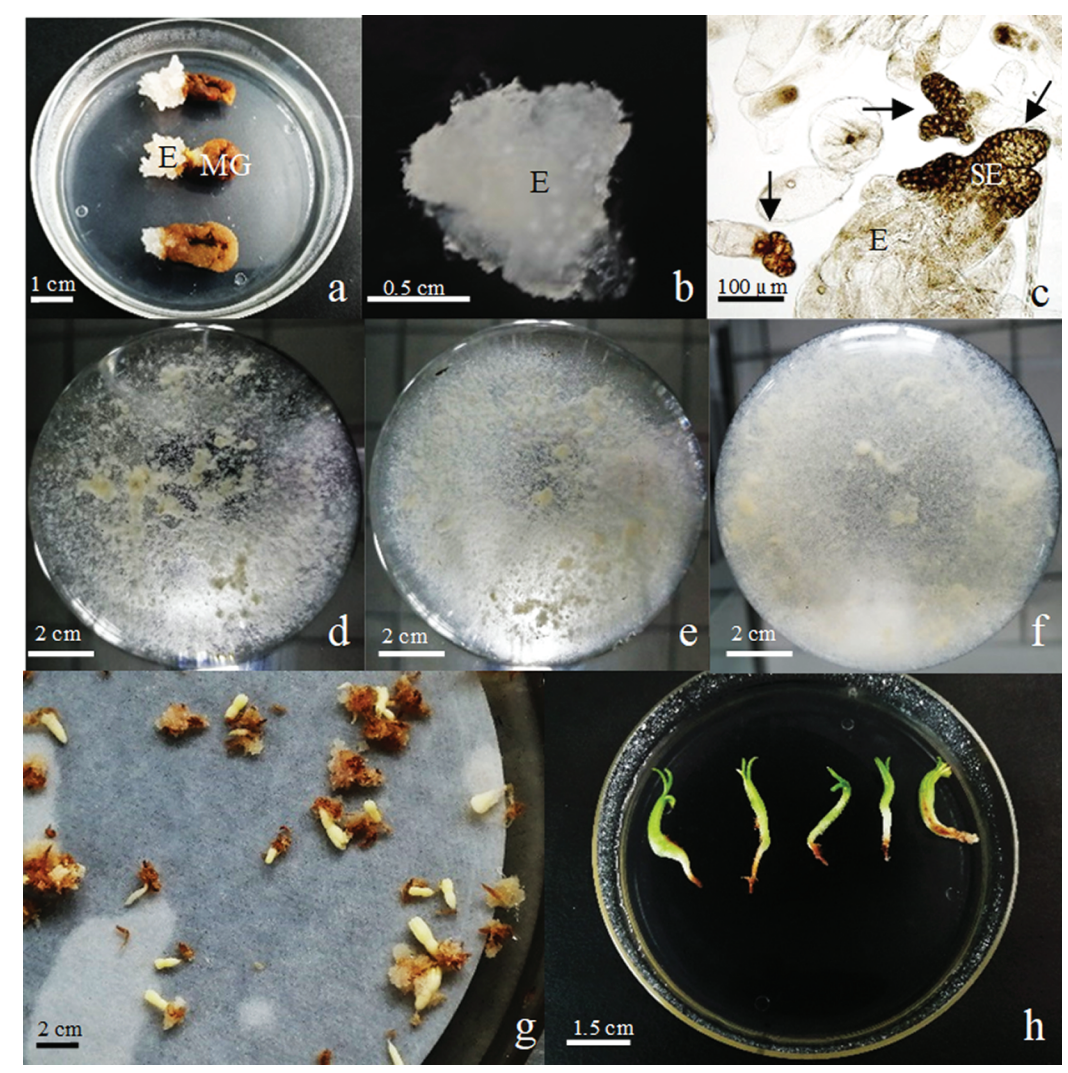

Figure 4: Observation of maturation of Korean pine somatic embryos. Note: a: Induction of ET of Korean pine (E: ET, MG: Megagametophyte), bar $=1 \mathrm{~cm}$; b: ET cultured on proliferation medium, bar $=0.5 \mathrm{~cm}$; $\mathrm{c}$ : microscopic observation of ET (SE: early somatic embryo, S-organized into bundle), bar $=100 \mu \mathrm{m}$; $\mathrm{d}$ : suspension culture of Korean pine ET $0 \mathrm{~d}, \mathrm{bar}=2 \mathrm{~cm}$, e: suspension culture of Korean pine ET for $7 \mathrm{~d}$, bar $=2 \mathrm{~cm}$; f: suspension culture of Korean pine ET for $14 \mathrm{~d}$, bar $=2 \mathrm{~cm}$; h: Cotyledonary SE, bar $=2 \mathrm{~cm}$; i: $\mathrm{SE}$ has completely germinated, $\mathrm{bar}=1.5 \mathrm{~cm}$

Stirring is a key factor on liquid cultures. It can not only regulate the growth and development of the culture by affecting the gas environment, but also promotes the full mixing of nutrients and metabolites [14]. On the other hand, the shear force generated by stirring can destroy the aggregation of ET, and promote either the formation or lysis of ET; excessive stirring can cause damage to cell development [26]. Therefore, the appropriate orbiting speed is important for the normal proliferation of ET in 
suspension culture [27]. In Korean pine suspension culture, the orbiting speed significantly affects the proliferation of ET, and the amount of proliferation gradually decreases as the orbiting speed increases [14,22]. A similar phenomenon also exists in stone pine: when the orbiting speed increased from $50 \mathrm{rpm}$ to $150 \mathrm{rpm}$, both SCV and DW were significantly reduced [22]. In Quercus suber L., when the stirring rate increased from $60 \mathrm{rpm}$ to $110 \mathrm{rpm}$, the yield of SEs gradually increased [14]. It shows that the proliferation of Korean pine ET gradually decreases with the increase of orbiting speed. The reason may be that ET cannot be decomposed into smaller aggregates at low orbiting speed, so loose accumulations are formed to obtain higher SCV, while at high orbiting speed, ET is decomposed to form smaller aggregates, forming tight accumulations to obtain lower SCV [22]. In addition, in our research, we found that the proliferation rate was higher in $200 \mathrm{~mL}$ Erlenmeyer flask than in $100 \mathrm{~mL}$ Erlenmeyer flask. Some studies have pointed out that for the same vessel volume of medium, a small diameter Erlenmeyer flask had a smaller gas exchange interface and larger liquid height. These two factors hindered the gas exchange, and the gas exchange affected the growth and development of the culture in liquid medium [14]. In Hordeum vulgare, it was found that the somatic embryogenesis potential of the culture in a $2 \mathrm{~L}$ suspension culture bioreactor was significantly reduced compared with the traditional small container [28]. Studies have shown that high oxygen concentrations are conducive to the proliferation of suspension, while low oxygen concentrations are conducive to transformation and differentiation [29]. It shows that the conditions of suspension culture should be appropriately changed according to the purpose of the culture.

In the study of Korean pine, we found that reducing the PGR concentration could promote the proliferation of ET; a similar phenomenon was observed in the suspension culture of stone pine [22]. The reason may be that the liquid suspension medium rapidly replaces nutrients on the surface of cells and promote the rapid nutrient absorption of cells. Therefore, compared to semi-solid medium, lowering nutrient levels in liquid medium can be advantageous [30]. In addition, during the suspension culture process, the growth of the culture depends on the carbon source in the medium. As a common carbon source in tissue cultures, sucrose can rapidly hydrolyze and increase the content of hexoses and storage compounds to increase cell proliferation speed [31]. However, some studies have pointed out that maltose can promote the development of SEs [32]. In our research, by comparing the two carbon sources, we found that sucrose was more suitable for tissue growth than maltose. Perhaps it was because maltose hydrolyzed slowly and could not provide nutrients in time, which limited the proliferation of ET [33].

From the perspective of plant SE yield, the formation of larger aggregates from ET is an important factor to reduce SE yield [13]. Decomposing ET into smaller aggregates with liquid medium can increase the growth rate of ET and promote the development of SE [10]. In our study, it was found that compared with ET proliferated on semi-solid medium, higher SE yield was obtained at $100 \mathrm{rpm}$, which was twice as much as that at $50 \mathrm{rpm}$. It shows that liquid culture can effectively promote the production of SEs, and increasing the orbiting speed can disperse ET into smaller aggregates, thereby increasing the yield of SEs [14]. In addition, as key substances to control growth and development, PGR concentration differences during the proliferation period affecting the proliferation of ET [34]. In our research, we found that PGR concentration changes had no significant effect on SE yield, but compared with other PGR treatments, ET propagated in low concentration PGR medium obtained the high SE yield. In Citrus suhuiensis, it was found that adding a lower concentration of BA could promote the proliferation of ET in the liquid, and the effective increase of the number of cells was higher than that of the medium containing high concentration of BA [35]. In addition, studies on Picea abies and Pinus sylvestris found that removing PGR from the proliferation medium could promote early SE development [36]. In the study of Pinus sylvestris, the yield of maturation SEs was increased by adding an auxin antagonist [37]. This indicates that the high content of auxin in ET may inhibit the differentiation and maturation of SEs [38]. Exogenous carbohydrates are essential for the induction, proliferation and maturation stages of somatic 
embryogenesis, during which they act as signal molecules, osmotic pressure and energy sources. Generally, sucrose is the most commonly used carbohydrate in the culture medium for the proliferation and maturation of coniferous SE [39]. Recent studies have pointed out that maltose could reduce ET proliferation and promote SE maturation [40]. Our research found that compared with sucrose, maltose not only inhibited the proliferation of ET during the proliferation process but also inhibited the somatic embryogenesis of ET. In plants, sucrose can be hydrolyzed into endogenous fructose and glucose, while maltose, due to slow hydrolysis, will lead to nutritional stress and restrict the carbon nutrition of cells [41]. Studies have found that endogenous sucrose during the proliferation of ET is positively correlated with the ability to develop normal SEs [42]. In Norway spruce, sucrose content accumulated in SEs even when SE maturation took place in sucrose-free medium [43]. This shows that at the proliferation stage, sucrose is necessary for somatic embryogenesis compared with maltose.

\section{Conclusion}

We evaluated the proliferation rate of ET under different inoculum-density, orbiting speed, PGR concentration, and carbon source, and came up with a culture plan suitable for effective proliferation of Korean pine ET. Fourty $\mathrm{mg} \cdot \mathrm{mL}^{-1}$ of Korean pine ET was transferred to a $200 \mathrm{~mL}$ Erlenmeyer flask containing $20 \mathrm{~mL}$ of liquid culture medium, incubated at $100 \mathrm{rpm}$ for $14 \mathrm{~d}$ and the maximum proliferation was obtained. After $14 \mathrm{~d}$ of culture, the ET was transferred to a maturation medium to obtain the highest SE yield ( $80 \mathrm{SEs} \cdot \mathrm{g}^{-1} \mathrm{FW}$ ). The determination of these parameters provides a theoretical basis for the further expansion of Korean pine into bioreactor cultivation. In addition, the ET proliferated in the liquid medium has the ability to maturation after being transferred to the maturation medium, and the SE yield is higher than that of the semi-solid medium. At the same time, this study also proves that proper speeds, lower PGR concentrations and sucrose are all important for SE yield. Our research shows that liquid suspension culture is feasible for improving the yield of Korean pine SEs. Therefore, in future research, we will try to further expand the culture volume, then use the bioreactor for cultivation, and use the temporary immersion bioreactor for SE maturation, to realize the automation and scaling up of Korean pine SE development.

Authors' Contributions: Y. L and S. HL conceived and designed the study. P. CX and G. F collected the plant materials and prepared SE samples for analysis. W. H and P. CH analyzed the results for experiments. Y. L, P. CX and W. H contributed to the writing of the manuscript and data analyses. S. HL revised the manuscript. All authors read and approved the final manuscript.

Acknowledgement: The authors thank two anonymous reviewers and the editor for comments that improved an earlier draft of this article.

Funding Statement: This work was supported by the Fundamental Research Funds for the Central Universities (2572020AW15) and the National Key R\&D Program of China (2017YFD0600600).

Conflicts of Interest: The authors declare that they have no conflicts of interest to report regarding the present study.

\section{References}

1. Jin, X., Pukkala, T., Li, F., Dong, L. (2017). Optimal management of Korean pine plantations in multifunctional forestry. Journal of Forestry Research, 28(5), 1027-1037. DOI 10.1007/s11676-017-0397-4.

2. Li, X., Liu, X. T., Wei, J. T., Li, Y., Tigabu, M. et al. (2020). Genetic improvement of Pinus koraiensis in China: Current situation and future prospects. Forests, 11(2), 148. DOI 10.3390/f11020148. 
3. Kim, Y. W., Moon, H. K. (2014). Enhancement of somatic embryogenesis and plant regeneration in Japanese red pine (Pinus densiflora). Plant Biotechnology Reports, 8(3), 259-266. DOI 10.1007/s11816-014-0319-2.

4. Salo, H. M., Sarjala, T., Jokela, A., Häggman, H., Vuosku, J. (2016). Moderate stress responses and specific changes in polyamine metabolism characterize Scots pine somatic embryogenesis. Tree Physiology 36(3), 392402. DOI 10.1093/treephys/tpv136.

5. Jo, L., Dos Santos, A. L., Bueno, C. A., Barbosa, H. R., Floh, E. I. (2014). Proteomic analysis and polyamines, ethylene and reactive oxygen species levels of Araucaria angustifolia (Brazilian pine) embryogenic cultures with different embryogenic potential. Tree Physiology, 34(1), 94-104. DOI 10.1093/treephys/tpt102.

6. Bozhkov, P. V., Ahn, I. S., Park, Y. G. (1997). Two alternative pathways of somatic embryo origin from polyembryonic mature stored seeds of Pinus koraiensis sieb et zucc. Canadian Journal of Botany, 75(3), 509512. DOI 10.1139/b97-055.

7. Gao, F., Peng, C., Wang, H., Shen, H., Yang, L. (2020). Selection of culture conditions for callus induction and proliferation by somatic embryogenesis of Pinus koraiensis. Journal of Forestry Research, 32, 483-491. DOI 10.1007/s11676-020-01147-1.

8. Peng, C., Gao, F., Wang, H., Shen, H., Yang, L. (2020). Optimization of maturation process for somatic embryo production and cryopreservation of embryogenic tissue in pinus koraiensis. Plant Cell, Tissue and Organ Culture, 144, 185-194. DOI 10.1007/s11240-020-01918-y.

9. Peng, C., Gao, F., Wang, H., Shen, H., Yang, L. (2020). Physiological and biochemical traits in Korean pine somatic embryogenesis. Forests, 11(5), 577. DOI 10.3390/f11050577.

10. Mamun, N. H., Aidun, C. K., Egertsdotter, U. (2018). Improved and synchronized maturation of Norway spruce (Picea abies (L.) H.karst.) somatic embryos in temporary immersion bioreactors. In Vitro Cellular \& Developmental Biology-Plant, 54(6), 612-620. DOI 10.1007/s11627-018-9911-4.

11. Filonova, L. H., Bozhkov, P. V., Arnold, S. V. (2000). Developmental pathway of somatic embryogenesis in Picea abies as revealed by time-lapse tracking. Journal of Experimental Botany, 51(343), 249-264. DOI 10.1093/jexbot/ 51.343.249.

12. Elhiti, M., Stasolla, C., Wang, A. (2013). Molecular regulation of plant somatic embryogenesis. In Vitro Cellular \& Developmental Biology-Plant, 49(6), 631-642. DOI 10.1007/s11627-013-9547-3.

13. Petrek, J., Zitka, O., Adam, V., Bartusek, K., Anjum, N. A. et al. (2015). Are early somatic embryos of the Norway spruce (Picea abies (L.) karst.) organised? PLoS One, 10(12), e0144093. DOI 10.1371/journal.pone.0144093.

14. Jiménez, J. A., Alonso-Blázquez, N., López-Vela, D., Celestino, C., Toribio, M. et al. (2011). Influence of culture vessel characteristics and agitation rate on gaseous exchange, hydrodynamic stress, and growth of embryogenic cork oak (Quercus suber L.) cultures. In Vitro Cellular \& Developmental Biology-Plant, 47(5), 578-588. DOI 10.1007/s11627-011-9399-7.

15. Egertsdotter, U., Ahmad, I., Clapham, D. (2019). Automation and scale up of somatic embryogenesis for commercial plant production, with emphasis on conifers. Frontiers in Plant Science, 10, 109. DOI 10.3389/ fpls.2019.00109.

16. Wang, G., Xu, C., Yan, S., Xu, B. (2019). An efficient somatic embryo liquid culture system for potential use in large-scale and synchronic production of anthurium andraeanum seedlings. Frontiers in Plant Science, 10, 29. DOI 10.3389/fpls.2019.00029.

17. Andrade, G. M., Nairn, C. J., Le, H. T., Merkle, S. A. (2009). Sexually mature transgenic American chestnut trees via embryogenic suspension-based transformation. Plant Cell Reports, 28(9), 1385-1397. DOI 10.1007/s00299009-0738-7.

18. Februyani, N., Widoretno, W., Indriyani, S. (2016). Effect of cell density and benzyl amino purine on the growth of somatic embryo of citrus mandarin batu 55 (Citrus reticulata blanco.) in liquid culture. The Journal of Experimental Life Science, 6(1), 1-4. DOI 10.21776/ub.jels.

19. Gupta, P. K., Durzan, D. J. (1985). Shoot multiplication from mature trees of Douglas-fir (Pseudotsuga menziesii) and sugar pine (Pinus lambertiana). Plant Cell Reports, 4(4), 177-179. DOI 10.1007/BF00269282. 
20. Klimaszewska, K., Park, Y. S., Overton, C., Maceacheron, I., Bonga, J. M. (2001). Optimized somatic embryogenesis in Pinus strobus L. In Vitro Cellular \& Developmental Biology-Plant, 37(3), 392-399. DOI 10.1007/s11627-001-0069-z.

21. Salaj, T., Blehová, A., Salaj, J. (2007). Embryogenic suspension cultures of Pinus nigra Arn.: Growth parameters and maturation ability. Acta Physiologiae Plantarum, 29(3), 225-231. DOI 10.1007/s11738-007-0028-3.

22. González-Cabrero, N., Ruiz-Galea, M., Alegre, J., Toribio, M., Celestino, C. (2018). Growth, morphology and maturation ability of Pinus pinea embryogenic suspension cultures. Plant Cell, Tissue and Organ Culture, 135(2), 331-346. DOI 10.1007/s11240-018-1467-9.

23. Ogita, S., Sasamoto, H., Kubo, T. (2000). Control of the development of somatic embryo of japanese conifers by the density of embryogenic cells in liquid culture. Transplant Production in the 21st Century, pp. 209-214, Springer, Dordrecht.

24. Al-Khayri, J. M. (2012). Determination of the date palm cell suspension growth curve, optimum plating efficiency, and influence of liquid medium on somatic embryogenesis. Emirates Journal of Food and Agriculture, 24(5), 444455. https://www.researchgate.net/publication/286156729.

25. Silveira, V., Floh, E. I. S., Handro, W., Guerra, M. P. (2004). Effect of plant growth regulators on the cellular growth and levels of intracellular protein, starch and polyamines in embryogenic suspension cultures of Pinus taeda. Plant Cell, Tissue and Organ Culture, 76(1), 53-60. DOI 10.1023/A:1025847515435.

26. Neděla, V., Hřib, J., Havel, L., Hudec, J., Runštuk, J. (2016). Imaging of Norway spruce early somatic embryos with the ESEM, cryo-sEM and laser scanning microscope. Micron, 84, 67-71. DOI 10.1016/j. micron.2016.02.011.

27. Hřib, J., Vooková, B., Neděla, V. (2015). Imaging of native early embryogenic tissue of Scots pine (Pinus sylvestris L.) by ESEM. Open Life Sciences, 10(1), 285-290. DOI 10.1515/biol-2015-0028.

28. Stirn, S., Hopstock, A., Lörz, H. (1994). Bioreactor cultures of embryogenic suspensions of barley (Hordeum vulgare L.) and maize (Zea mays L.). Journal of Plant Physiology, 144(2), 209-214. DOI 10.1016/S0176-1617 (11)80545-6.

29. de Feria, M., Jiménez, E., Barbón, R., Capote, A., Chávez, M. et al. (2003). Effect of dissolved oxygen concentration on differentiation of somatic embryos of Coffea arabica cv. catimor 9722. Plant Cell, Tissue and Organ Culture, 72(1), 1-6. DOI 10.1023/A:1021202305692.

30. Gupta, P. K., Timmis, R. (2005). Mass propagation of conifer trees in liquid cultures-progress towards commercialization. Liquid Culture Systems for in Vitro Plant Propagation, pp. 389-402. Springer, Dordrecht.

31. Santos, A. L. W. D., Silveira, V., Steiner, N., Maraschin, M., Guerra, M. P. (2010). Biochemical and morphological changes during the growth kinetics of araucaria angustifolia suspension cultures. Brazilian Archives of Biology and Technology, 53(3), 497-504. DOI 10.1590/S1516-89132010000300001.

32. Ming, N. G., Binte Mostafiz, S., Johon, N. S., Abdullah Zulkifli, N. S., Wagiran, A. (2019). Combination of plant growth regulators, maltose, and partial desiccation treatment enhance somatic embryogenesis in selected Malaysian rice cultivar. Plants, 8(6), 144. DOI 10.3390/plants8060144.

33. Blanc, G., Lardet, L., Martin, A., Jacob, J. L., Carron, M. P. (2002). Differential carbohydrate metabolism conducts morphogenesis in embryogenic callus of Hevea brasiliensis (Mull. Arg.). Journal of Experimental Botany, 53(373), 1453-1462. DOI 10.1093/jxb/53.373.1453.

34. Vondráková, Z., Krajňáková, J., Fischerová, L., Vágner, M., Eliášová, K. (2016). Physiology and role of plant growth regulators in somatic embryogenesis. Vegetative Propagation of Forest Trees, 123-169.

35. Agisimanto, D., Noor, N. M., Ibrahim, R., Mohamad, A. (2012). Efficient somatic embryo production of Limau madu (Citrus suhuiensis Hort. ex Tanaka) in liquid culture. African Journal of Biotechnology, 11(12), 2879-2888. DOI 10.5897/AJB.

36. Breton, D., Harvengt, L., Trontin, J. F., Bouvet, A., Favre, J. M. (2005). High subculture frequency, maltose-based and hormone-free medium sustained early development of somatic embryos in maritime pine. In Vitro Cellular \& Developmental Biology-Plant, 41(4), 494. DOI 10.1079/IVP2005671. 
37. Abrahamsson, M., Valladares, S., Larsson, E., Clapham, D., von Arnold, S. (2012). Patterning during somatic embryogenesis in Scots pine in relation to polar auxin transport and programmed cell death. Plant Cell, Tissue and Organ Culture, 109(3), 391-400. DOI 10.1007/s11240-011-0103-8.

38. Carneros, E., Toribio, M., Celestino, C. (2017). Effect of ABA, the auxin antagonist PCIB and partial desiccation on stone pine somatic embryo maturation. Plant Cell, Tissue and Organ Culture, 131(3), 445-458. DOI 10.1007/ s11240-017-1296-2.

39. Schuller, A., Reuther, G. (1993). Response of abies alba embryonal-suspensor mass to various carbohydrate treatments. Plant Cell Reports, 12(4), 199-202. DOI 10.1007/BF00237053.

40. Merkle, S. A., Montello, P. M., Reece, H. M., Kong, L. (2014). Somatic embryogenesis and cryostorage of eastern hemlock and carolina hemlock for conservation and restoration. Trees, 28(6), 1767-1776. DOI 10.1007/s00468014-1084-0.

41. Lipavská, H., Konrádová, H. (2004). Somatic embryogenesis in conifers: The role of carbohydrate metabolism. In Vitro Cellular \& Developmental Biology-Plant, 40(1), 23-30. DOI 10.1079/IVP2003482.

42. Businge, E., Brackmann, K., Moritz, T., Egertsdotter, U. (2012). Metabolite profiling reveals clear metabolic changes during somatic embryo development of Norway spruce (Picea abies). Tree Physiology, 32(2), 232244. DOI 10.1093/treephys/tpr142.

43. Kubeš, M., Drážná, N., Konrádová, H., Lipavská, H. (2014). Robust carbohydrate dynamics based on sucrose resynthesis in developing Norway spruce somatic embryos at variable sugar supply. In Vitro Cellular \& Developmental Biology-Plant, 50(1), 45-57. DOI 10.1007/s11627-013-9589-6. 